\title{
Introduction to the May 2020 Issue
}

\section{Charles B. Hodges ${ }^{1}$}

Published online: 21 May 2020

(C) Association for Educational Communications \& Technology 2020

The current issue of TechTrends is reaching you during an incredible period in our world's history. I hope that each of you are managing well enough during the COVID19 pandemic. I know that times are challenging for many people. The TechTrends community has been amazing during this time with great authors submitting their work, reviewers providing prompt and meaningful feedback, guest editors working diligently on special issues, the Springer production team striving for excellence, etc. It is always a pleasure working as the Editor-in-Chief of TechTrends.

The May 2020 issue is filled with several items for you to consider. The issue opens with columns: History Corner, Graduate Member Musings, Rethinking Technology \& Creativity in the twenty-first Century, and ICT International. Those columns are followed by 14 original papers on a variety of topics and a special section of four award papers from the 13th International Malaysian Educational Technology Convention, which was held in August 2019. You can read an introduction to that special section by Dr. Chau Kien Tsong immediately preceding those papers. After the award section, the issue closes with two more columns: Leading Matters, and Book Reviews.

As always, if you are interested in submitting a manuscript to TechTrends, or if you want to be a reviewer, please contact me. Encourage your colleagues to submit their work to TechTrends, to read TechTrends, and to consider joining AECT! If you have a question about the journal, my phone number is $912-478-0497$ and my email address is chodges@georgiasouthern.edu. Email is always the best way to reach me. Also, you can follow TechTrends on Twitter: @AECTTechTrends.

Publisher's Note Springer Nature remains neutral with regard to jurisdictional claims in published maps and institutional affiliations.
Charles B. Hodges

chodges@georgiasouthern.edu

1 Georgia Southern University, Statesboro, GA, USA 